\title{
Prehistory
}

\section{Thoughts from artefacts: towards a cognitive archaeology}

from Alun $M$. Anderson

IN a recent publication*, giving the text of his inaugural lecture as Disney Professor of Archaeology at Cambridge University, Colin Renfrew argues for the opening up of a new field of 'cognitive archaeology' - an archaeology which would draw on such diverse subjects as ethology and artificial intelligence as well as those more traditionally associated with archaeology. The central point of his argument is that the archaeological record contains information not only about human technology, economy and society, but also about human reasoning, the concepts and ways of thought shared by the citizens of a particular culture.

What particularly emboldened Renfrew to suggest that a cognitive archaeology might be possible is the recent, and successful, emergence of social archaeology. It was only some twenty-five years ago that it was argued that a social archaeology would have 'no sound intellectual basis at all', since 'historical events and essential social divisions of prehistoric peoples don't find an adequate expression in material remains, it cannot be right to try to arrive at a knowledge of them by archaeological interpretation'. As it turned out, social archaeologists did find ways of revealing something of the social structure of societies from archaeological remains.

A good example, described by Renfrew, comes from the study of geographical patterns of early settlements. Using as data the sizes and locations of settlements revealed by archaeological survey, it is possible to recognize hierarchical patterns that indicate the political geography of the area at the time in question. The validity of the technique can easily be seen by applying it to the present pattern of towns and cities a political map of modern Europe emerges. The recognition of hierarchy at this level immediately suggests a corresponding social hierarchy; of 'central persons to accompany the central places'.

A second example comes from the study of cemeteries where it is possible to examine the goods accompanying each individual burial. Obviously, the distribution of goods according to sex, age and so on can lead to a good idea of the social structure of the community from which they came.

In some senses social archaeology is on the road towards cognitive archaeology, for it is reasonable to infer that the social divisions of a society reflect, or are reflected in, corresponding concepts about that society. Obviously though, attempts

Renfrew, C. Towards a Cognitive Archaeology (Cambridge University Press, 1982). to understand the modes of thought and beliefs of a vanished society are going to present special problems of their own, which direct comparison with anthropological studies of living groups do not in themselves solve. Renfrew is optimistic that sets of analytical procedures are possible which are not simply based on an 'inspired exercise of the creative imagination' like so many commentaries on ancient art. Certainly, going further back in time, much has already been accomplished in recording the emergence of characteristics that are believed unique in man. These include the use of tools, and perhaps language, with Homo habilis at around 2 Myr BP; the use of pigments (perhaps implying body decoration) with Homo erectus at 1.5 Myr BP; and, with Homo sapiens, the use of fire, development of specialized 'tool kits', apparently delibarate disposal of the dead, cave painting, the making of repeated marks in a manner indicative of couting; and then, later still, the emergence of agriculture.

A problem remains, however. To what extent does the emergence of a particular behaviour - even an apparently intelligent one - tell us about the cognitive processes that produce it? We only have to go back to the turn of the century to see the 'agriculture' practiced by some species of ants, and the navigation and homing abilities of insects and birds, used as evidence of 'intelligence' in animals. What the then new science of ethology did was to show that apparently sophisticated behaviours can be based on very simple models of the world. Indeed, there are many archaeologists who would favour the view that farming arose through a trial-and-error process whch tells us nothing of man's cognitive abilities.

An important distinction can, however, be drawn, for the archaeological record contains not just information about 'doing things' but also of 'thinking about doing things'. A clear example is seen in the carefully made stone cubes found in the Mohenjo-daro site of the Indus Valley civilization. The cubes have weights that would be produced by multiplying a constant unit of weight (actually $0.836 \mathrm{~g}$ ) by such integers as $1,4,8$ up to 64 , then 320 and 1,600 . This is purely archaeological evidence, but it allows us to assert, not just that the society had a concept of weight, units and numeration, but surely that the society had a concept of 'weighing'; that is, of equivalence of weight among objects made of different materials, and hence notions of 'value' and of rates of exchange between commodities. An important difference emerges here in the representation (or 'mapping') of weight and the 'map- ping' seen in the animal world, as exemplified in the dance language of the bee. It is only in the former case that a mapping device - the system of weights has been constructed.

Clear archaeological evidence for deliberate action carried out to a preconceived design is also revealed in the planning of towns; the streets of Mohenjodaro, for example, are laid out on firm rectilinear principles. Caution will be needed in interpreting evidence of planning, for many simple rules of organic growth can result in symmetrical designs, and apparent order in town plans can emerge without plan at all; but these do not seem insurmountable obstacles to research.

Renfrew appears at his most cautious when he discusses attempts to infer religious practice from archaeological finds - an area where the nonarchaeologist might feel that the archaeologist is most free to speculate on the thought processes and beliefs of ancient cultures. Perhaps it is abuse of that freedom that makes Renfrew argue for efforts to find a much more rigorous methodology for the study of religion from material remains of religious practices. Indeed, even in the case of cave art, we have no clear and unequivocal method of demonstrating that a given form is a depiction; there are numerous natural forms that mimic the creations of man.

What Renfrew is really after is a coherent body of theory which will allow inferences about the cognitive processes of past societies to be made without, as he says, 'dizzy leaps'. But how are cognitive processes to be categorized and described? Ethology and artificial intelligence, on which Renfrew hopes to draw, are full of cautionary tales. Numerous attempts have been made to categorize 'cognitive' or learning 'abilities' among diverse animal groups and to set up phylogenetic levels of 'intelligence'. All have failed to overcome the problem that each species learns in its own way, a way that is adapted to the particular environment in which it lives, so that no general categories of learning ability emerge. Again, studies in artificial intelligence have shown us the difficulty of classifying tasks without knowing exactly how they are carried out; it is often the apparently simple skills that require the most complex computations.

Renfrew is aware of these problems but remains optimistic that 'thoughts' do find effective expression in the archaeological record and ways can be found of studying them. In the long term he may well prove right, but, at least for the time being, cognitive archaeology may have to be content, in Renfrew's words, to 'tread an uneasy path between the pretentiously jargon laden and the blindingly obvious'.

Alun M. Anderson is the editor of the News and Views section of Nature. 